\title{
A Survival Score for Patients Assigned to Palliative Radiotherapy for Metastatic Bladder Cancer
}

\author{
DIRK RADES ${ }^{1}$, LISA MANIG $^{1}$, STEFAN JANSSEN $^{1,2}$ and STEVEN E. SCHILD ${ }^{3}$ \\ ${ }^{1}$ Department of Radiation Oncology, University of Lübeck, Lübeck, Germany; \\ ${ }^{2}$ Private Practice of Radiation Oncology, Hannover, Germany; \\ ${ }^{3}$ Department of Radiation Oncology, Mayo Clinic, Scottsdale, AZ, U.S.A.
}

\begin{abstract}
Aim: To create a survival score for patients with metastatic bladder cancer. Patients and Methods: In 46 irradiated patients, six characteristics were evaluated for their association with survival: Age, gender, Karnofsky performance scale, initial stage (American Joint Committee on Cancer), number of metastatic sites, and interval between bladder cancer diagnosis and palliative radiotherapy. Characteristics showing a trend $(p<0.15)$ were incorporated into the score. Six-month survival rates were divided by 10. Patients' scores were derived by totaling the scores of these characteristics. Results: Performance scale $(p=0.14)$, stage $(p=0.055)$ and number of metastatic sites $(p=0.10)$ showed a trend for association with survival. Patients' scores were 6, 7, 8, 10 or 12 points, with corresponding 6-month survival rates of 20\%, 0\%, $0 \%, 46 \%$ and $45 \%(p=0.038)$. Two groups were created, with 6-8 and with 10-12 points, with 6-month survival rates of $9 \%$ and $46 \%$ $(p=0.002)$, respectively. Conclusion: A new survival score was developed. Patients with 6-8 points should receive less aggressive treatments for metastatic bladder cancer. Those with 10-12 points may receive more intensive approaches.
\end{abstract}

Patients who present with metastatic bladder cancer generally have a poor prognosis, surviving only very few months (1). However, some patients may live considerably longer. If a patient is able to withstand palliative chemotherapy, their remaining lifetime may be extended with systemic treatments. Patients who are unable to tolerate chemotherapy are often referred to a radiation oncologist for palliative irradiation aiming to relieve or prevent debilitating

This article is freely accessible online.

Correspondence to: Professor Dirk Rades, Department of Radiation Oncology, University of Lübeck, Ratzeburger Allee 160, D-23552 Lübeck, Germany. Tel: +49 4515006661 , e-mail: rades.dirk@gmx.net

Key Words: Metastatic bladder cancer, radiotherapy, palliation, personalized treatment, survival score. symptoms $(2,3)$. In such palliative situations personalized treatment concepts account for the patient's preferences and needs, as well as their expected survival time.

Patients with a very short remaining lifespan should ideally not receive too intensive or time-consuming treatment programs. In contrast, patients with a much more favorable prognosis could benefit from more intensive approaches with higher total radiation doses. This concept was reported for radiotherapy of metastatic disease from other primary tumor types $(4,5)$. Tailoring a treatment program to an individual patient receiving palliative radiotherapy of metastatic bladder cancer during clinical routine would be easier if a simple tool was available allowing an estimation of such a patient's survival time. This study was conducted to develop such an instrument, specifically designed for patients irradiated for metastatic bladder cancer. Since a previous study suggested that the prognosis of these patients may be influenced by the radiation dose, only patients who received an equivalent dose in 2 Gy fractions (EQD2) of more than $30 \mathrm{~Gy}$ (6) were included.

\section{Patients and Methods}

In 46 patients who received palliative radiotherapy with an EQD2 greater than 30 Gy for metastatic bladder cancer, six characteristics were retrospectively evaluated with respect to their impact on survival. The six characteristics (Table I) were age at palliative radiotherapy ( $\leq 70$ vs. $>70$ years, median $=70$ years), gender, Karnofsky performance scale (KPS $\leq 60 \% v s .>60 \%$, median KPS $=70 \%$ ), initial tumor stage according to the American Joint Committee on Cancer (7) (AJCC stage $\leq 3 v s$. 4, median=3), number of organ sites involved by metastatic disease ( $1 v s . \geq 2$ sites, median=1), and the interval between the first diagnosis of bladder cancer and palliative radiotherapy $(\leq 12$ vs. $>12$ months, median=13 months).

For the survival analyses, the Kaplan-Meier method was used supplemented by the log-rank test (8). Those characteristics having at least a trend towards an impact on survival $(p<0.15)$ were incorporated into the survival score. For this score, the 6-month survival rates of the corresponding characteristics were taken and divided by 10 . The prognostic score for a single patient was derived by adding the scores of all characteristics that showed a trend in the survival analysis. 
Table I. Distribution of the six evaluated characteristics.

\begin{tabular}{lcc}
\hline & $\begin{array}{c}\text { Number of } \\
\text { patients }\end{array}$ & $\begin{array}{c}\text { Proportion } \\
(\%)\end{array}$ \\
\hline $\begin{array}{l}\text { Age at palliative radiotherapy } \\
\quad \text { 70 Years }\end{array}$ & 54 \\
$\quad>70$ Years & 25 & 46 \\
Gender & 21 & \\
$\quad$ Female & 9 & 20 \\
$\quad$ Male & 37 & 80 \\
KPS & & \\
$\quad \leq 60$ & 22 & 48 \\
$\quad>60$ & 24 & 52 \\
Initial AJCC stage & 23 & 50 \\
$\quad 1-3$ & 21 & 46 \\
$\quad \geq 4$ & 2 & 4 \\
$\quad$ Unknown & & \\
Number of involved metastatic sites & 27 & 59 \\
$\quad 1$ & 19 & 41 \\
$\quad \geq 2$ & & \\
Interval between diagnosis of bladder cancer & & \\
and palliative radiotherapy & & \\
$\quad \leq 12$ Months & 22 & 48 \\
$\quad>12$ Months & 24 & 52 \\
\hline
\end{tabular}

AJCC: American Joint Committee on Cancer (7); KPS: Karnofsky performance scale.
Table II. Three- and 6-month survival rates of the evaluated characteristics.

\begin{tabular}{lccc}
\hline & $\begin{array}{c}\text { At } 3 \text { months } \\
(\%)\end{array}$ & $\begin{array}{c}\text { At } 6 \text { months } \\
(\%)\end{array}$ & $P$ \\
$\quad$ & & & \\
\hline $\begin{array}{l}\text { Age at palliative radiotherapy } \\
\quad \leq 70 \text { Years }\end{array}$ & 56 & 36 & 0.22 \\
$\quad>70$ Years & 43 & 19 & \\
Gender & 44 & 22 & \\
$\quad$ Female & 51 & 30 & 0.73 \\
$\quad$ Male & & & \\
KPS & 45 & 18 & \\
$\quad \leq 60$ & 54 & 38 & 0.14 \\
$\quad>60$ & & & \\
Initial AJCC stage & 52 & 39 & 0.055 \\
$\quad 1-3$ & 52 & 19 & \\
$\quad \geq 4$ & & & \\
$\quad$ Unknown & & & \\
Number of involved & & & \\
metastatic sites & & & \\
$\quad 1$ & 56 & & \\
$\quad \geq 2$ & 42 & & \\
Interval between diagnosis & & & \\
of bladder cancer and & & & \\
palliative radiotherapy & & & \\
$\quad \leq 12$ Months & 59 & & \\
$\quad>12$ Months & 42 & & \\
\hline
\end{tabular}

AJCC: American Joint Committee on Cancer (7); KPS: Karnofsky performance scale.

Table III. Characteristics incorporated in the score and corresponding scoring points.

\begin{tabular}{lcc}
\hline & $\begin{array}{c}\text { Survival rate } \\
\text { at } 6 \text { months } \\
(\%)\end{array}$ & $\begin{array}{c}\text { Scoring } \\
\text { points }\end{array}$ \\
\hline KPS & & \\
$\quad 60$ & 18 & 2 \\
$\quad>60$ & 38 & 4 \\
Initial AJCC stage & 39 & 4 \\
$\quad 1-3$ & 19 & 2 \\
$\geq 4$ & & \\
$\quad$ Unknown & & \\
Number of involved metastatic sites & 37 & 4 \\
1 & 16 & 2 \\
$\geq 2$ & \\
\hline
\end{tabular}

AJCC: American Joint Committee on Cancer (7); KPS: Karnofsky performance scale.

approaches of systemic treatments (10-13). Personalized medicine is another promising approach to improving the prognosis of patients with metastatic cancer, including those with metastases from bladder cancer. To optimally utilize personalized anticancer treatment, the treating physicians have to be able to estimate an individual patient's remaining 


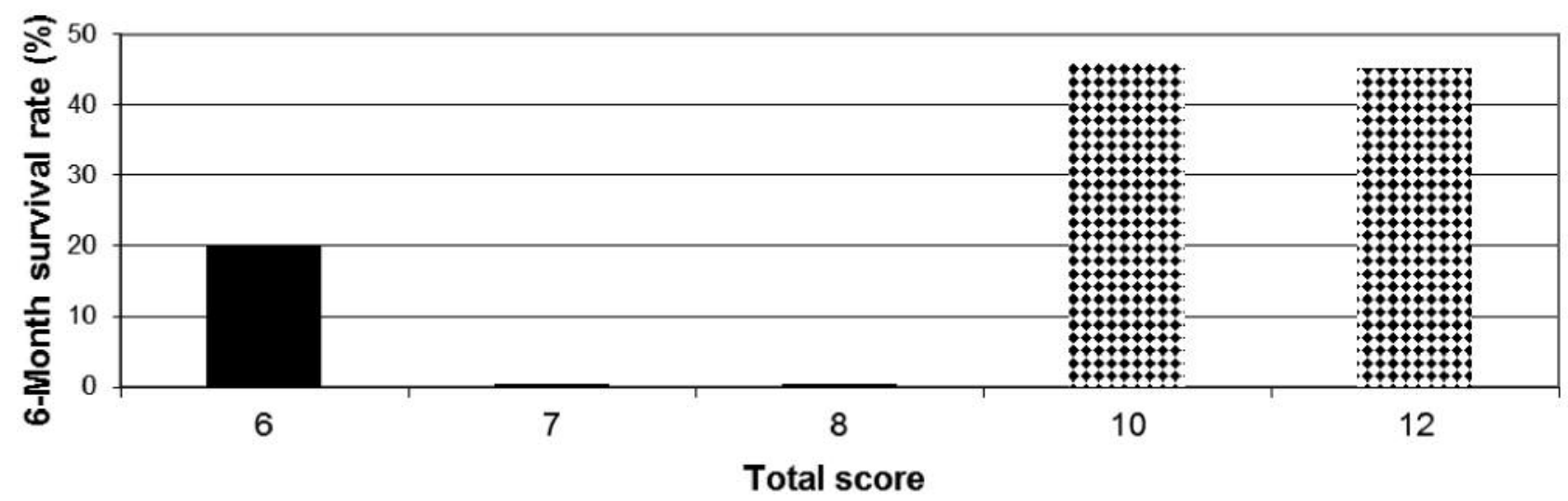

Figure 1. The 6-month survival rates obtained from the Kaplan-Meier analysis in relation to the scores calculated for each single patient.

lifespan as precisely as possible. To achieve this goal, precise knowledge of predictors of survival is very helpful. Moreover, a simple scoring tool that can easily be used in clinical routine is desirable to allow a quick and appropriate selection of an optimal treatment approach for an individual patient.

In the current study, such a tool was created for patients who received palliative radiotherapy for metastatic bladder cancer. Based on three potential prognostic factors, namely KPS, initial AJCC stage and the number of sites involved by metastatic disease, we derived two prognostic groups with significantly different 6-month survival rates. Patients with a total score of 6-8 had a 6-month survival rate of only $9 \%$. Therefore, these patients can be considered candidates for a short and less intensive radiotherapy program. Several studies of palliative radiotherapy for metastases from solid tumors including bladder cancer have shown that a significant relief of symptoms can be achieved also with short radiotherapy programs that last only one day or one week. This has for example been demonstrated already for irradiation of painful bone metastases, metastatic spinal cord compression and brain metastases $(2,3,14-17)$.

In the group of patients who achieved a score of 10-12 in the present study the 6-month survival rate was $46 \%$, i.e. much better than in the groups with 6-8 points. Therefore, these patients may be considered for longer-lasting radiotherapy programs including higher total doses greater than 30 Gy. Previous studies of palliative radiotherapy for metastatic spinal cord compression and brain metastases have shown that patients with a better survival prognosis benefit from higher doses in terms of improved local control and survival $(4,5)$. When following these recommendations, one should be aware of the limitations of the present study, namely its retrospective nature and the

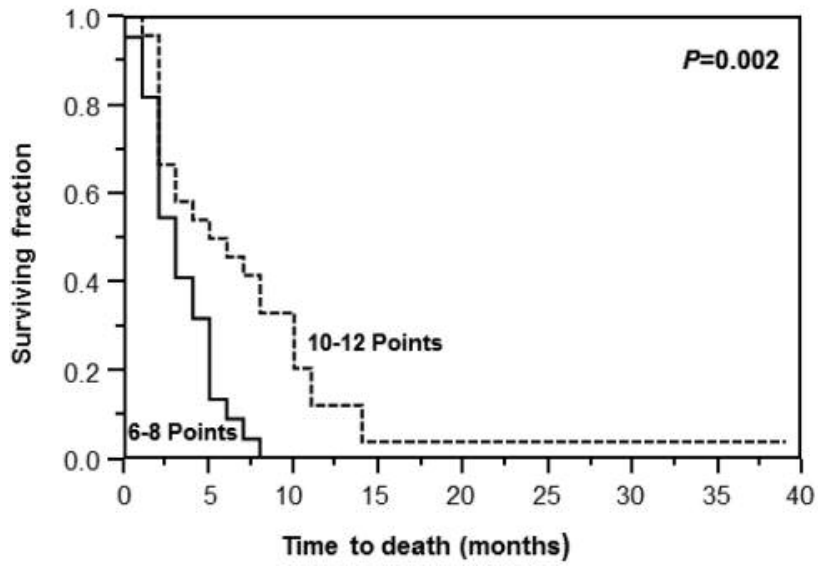

Figure 2. Kaplan-Meier curves of the overall survival of the two prognostic groups: with 6-8 points and 10-12 points (p-value obtained from log-rank test).

relatively small number of patients. Retrospective studies bear a certain risk of including hidden biases. In order to reduce the risk of bias, only patients receiving an EQD2 of more than $30 \mathrm{~Gy}$ were included in this study (6). Ideally, the results would be confirmed in a prospective trial. However, since patients with bladder cancer account for only about $2 \%$ of all patients with cancer, such a prospective trial with an adequate statistical power cannot be expected soon (18).

In summary, a new survival score was developed for patients receiving palliative radiotherapy for metastatic bladder cancer. Patients who achieve 6-8 points should receive less burdensome and less time-consuming treatments. In patients achieving 10-12 points, more intensive approaches may result in better local control and survival. 


\section{Conflicts of Interest}

On behalf of all Authors, the corresponding Author states that there is no conflict of interest related to this study.

\section{References}

1 Guancial EA, Roussel B, Bergsma DP, Bylund KC, Sahasrabudhe D, Messing E, Mohile SG and Fung C: Bladder cancer in the elderly patient: challenges and solutions. Clin Interv Aging 10: 939-949, 2015.

2 Rades D, Walz J, Schild SE, Veninga T and Dunst J: Do bladder cancer patients with metastatic spinal cord compression benefit from radiotherapy alone? Urology 69: 1081-1085, 2007.

3 Rades D, Meyners T, Veninga T, Stalpers LJA and Schild SE: Hypofractionated whole-brain radiotherapy for multiple brain metastases from transitional cell carcinoma of the bladder. Int J Radiation Oncology Biol Phys 78: 404-408, 2010.

4 Rades D, Panzner A, Rudat V, Karstens JH and Schild SE: Dose escalation of radiotherapy for metastatic spinal cord compression (MSCC) in patients with relatively favorable survival prognosis. Strahlenther Onkol 187: 729-735, 2011.

5 Rades D, Panzner A, Dziggel L, Haatanen T, Lohynska R and Schild SE: Dose-escalation of whole-brain radiotherapy for brain metastasis in patients with a favorable survival prognosis, Cancer 118: 3853-3859, 2012.

6 Manig L, Käsmann L, Janssen S and Rades D: Predicting survival after irradiation of metastases from transitional carcinoma of the bladder. Anticancer Res 36: 6663-6665, 2016.

7 Edge SB, Byrd DR, Compton CC, Fritz AG, Greene FL and Trotti A (eds.): AJCC Cancer Staging Manual (7th edition). New York, NY, Springer, 2010.

8 Kaplan E and Meier P: Nonparametric estimation from incomplete observation. J Am Stat Assoc 53: 457-481, 1958.

9 Goldman SM, Fajardo AA, Naraval RC and Madewall JE: Metastatic transitional cell carcinoma from the bladder: Radiographic manifestations. Am J Roentgenol 132: 419-425, 1979.

10 Kilari D, Iczkowski KA, Pandya C, Robin AJ, Messing EM, Guancial E and Kim ES: Copper transporter-CTR1 expression and pathological outcomes in platinum-treated muscle-invasive bladder cancer patients. Anticancer Res 36: 495-501, 2016.

11 Jana BR and Zhou Y: Novel molecular targets for the therapy of urothelial cancer. Anticancer Res 35: 4557-4567, 2015.
12 Lea MA, Guzman Y and Desbordes C: Inhibition of growth by combined treatment with inhibitors of lactate dehydrogenase and either phenformin or inhibitors of 6-phosphofructo-2-kinase/ fructose-2,6-bisphosphatase 3. Anticancer Res 36: 1479-1488, 2016.

13 Nakagawa YU, Nagaya H, Miyata T, Wada Y, Oyama T and Gotoh A: Piperazine-based alpha-1 AR blocker, naftopidil, selectively suppresses malignant human bladder cells via induction of apoptosis. Anticancer Res 36: 1563-1570, 2016.

14 Rades D, Stalpers LJA, Veninga T, Schulte R, Hoskin PJ, Obralic N, Bajrovic A, Rudat V, Schwarz R, Hulshof MC, Poortmans $\mathrm{P}$ and Schild SE: Evaluation of five radiation schedules and prognostic factors for metastatic spinal cord compression. J Clin Oncol 23: 3366-3375, 2005.

15 Rades D, Šegedin B, Conde-Moreno AJ, Garcia R, Perpar A, Metz M, Badakhshi H, Schreiber A, Nitsche M, Hipp P, Schulze W, Adamietz IA, Norkus D, Rudat V, Cacicedo J and Schild SE: Radiotherapy with 4 Gy $\times 5$ versus $3 \mathrm{~Gy} \times 10$ for metastatic epidural spinal cord compression: Final results of the SCORE-2 trial (ARO 2009/01). J Clin Oncol 34: 597-602, 2016.

16 Lutz S, Berk L, Chang E, Chow E, Hahn C, Hoskin P, Howell D, Konski A, Kachnic L, Lo S, Sahgal A, Silverman L, von Gunten C, Mendel E, Vassil A, Bruner DW and Hartsell W; American Society for Radiation Oncology (ASTRO). Palliative radiotherapy for bone metastases: an ASTRO evidence-based guideline. Int J Radiat Oncol Biol Phys 79: 965-976, 2011.

17 Tsao MN, Rades D, Wirth A, Lo SS, Danielson BL, Gaspar LE, Sperduto PW, Vogelbaum MA, Radawski JD, Wang JZ, Gillin MT, Mohideen N, Hahn CA and Chang EL: Radiotherapeutic and surgical management for newly diagnosed brain metastasis(es): An American Society for Radiation Oncology evidence-based guideline. Pract Radiat Oncol 2: 210-25, 2012.

18 Jemal A, Siegel R, Ward E, Murray T, Xu J, Smigal C and Thun M: Cancer statistics, 2006. Cancer J Clinic 56: 106-130, 2006.

Received January 6, 2017

Revised February 10, 2017

Accepted February 13, 2017 